\title{
Analysis of the quality of public urban space through a graphical analysis method
}

\author{
A. Galiano \& V. Echarri \\ Department of Building Technology, University of Alicante, Spain
}

\begin{abstract}
The southeast coast of Spain has been one of the examples of the construction bubble that affected this country in the last years. Everything was under construction and any piece of land may be built up. The results of this crazy process are chaotic urban structures and cities with a very low level of activity where a lack of quality at urban space conditions citizens' life. Orihuela is a very complex municipality where up to 25 urban settlements can be found. All of them received some kind of urban development during these years but, in particular, the city of Orihuela and the Coast, $7 \mathrm{~km}$ of gated communities with no city structure. The city urban master plan is under revision at the moment and a different approach was demanded by the city council. A public participating process was opened where a graphical analysis method was applied. The RGBG Strategic Method gathers and classifies the different uses at public space in layers. The result of the process shows quantitative and qualitative data, objective and subjective information that allows the urban designer to get conclusions about the quality of public space and by evaluating the level of activity provide solutions to the conflicts found on the urban frame.
\end{abstract}

Keywords: graphic analysis, urban design, urban development, infrastructures.

\section{Introduction}

During the property boom in Spain, most towns in the south east of the country underwent a process of aggressive urban growth which, at times, resulted in chaotic situations that had some serious repercussions on the quality of life of their inhabitants. The lack of any clear growth criterion led to the creation of impersonal urban spaces with no adequate balance of activities carried out in these areas. 
The urban conflicts inherited by those who are currently responsible for planning in these towns have led them to devise strategies to intervene in the built environment rather than design new expansions in an endeavour to recover at least a minimum level of quality in town spaces.

Consideration of the urban space as a structure in which common initiatives converge in the public interest originated in the 18th century when G. Nolli in Nuova Topografía di Roma [1], suggested representation of the urban space in a figure and ground plan and including the ground floors of public buildings, defining the public space as any area of collective use, irrespective of its ownership. It was the Danish urban planner Jan Gehl in his book "Life between buildings, using public space" [2], who claimed that in order to achieve adequate quality of urban space there should be a balance of activities so that sustained use of the space is made throughout the day.

The possibility of analysing urban developments arising as the town grows, through quality of the urban public space is proposed as a valid option, as not only are the physical values evaluated, but also the activities carried out in those areas are considered. Objective and subjective parameters are related, offering a real approach to the way in which urban space is used.

\section{Improving urban environment}

Improving the urban frame, detecting and resolving conflicts are one of the greatest concerns of those responsible for the growth and development of towns. Throughout history, geometric urban designs gave rise to interventions justified in improving living conditions in cities. Cerdá's proposal for the city of Barcelona is a recognised example, in which for the first time in Spain, priority was given to "content", that is people over the "structure", buildings [3].

In the early 20th century, with the modern movement, design of urban spaces developed to create a rational and experimental approach, in which specialisation in the urban area led to extreme results such as those of Brasilia. Nevertheless, it was during the latter years of the 20th century that innovative methods began to be developed in the urban environment and town's inhabitants became the salient factor within urban public space.

One approach that focuses on finding a relation between the physical environment and human perception of spaces is that supporting the theories of Reijndorp and Hajer in the book "In search of the new public domain" [4]. Based on an analysis of the cultural structure of the city, the author considers that the value of the public domain is conditioned by the intensity, diversity, overlapping and interaction between uses and users. Lynch promotes a similar theory in his "The image of the City" [5] in which he claims that a person in an urban situation uses his own mental map for guidance. The central concept of the method is the legibility of the urban space defined as any element of the urban environment that can be interpreted.

As an analytical tool of urban morphology, Hillier and Hanson developed Space Syntax [6], which is based on the fact that all spaces are interconnected in an urban environment. Originally it was designed as a tool to help architects 
simulate the possible social effects of their urban designs, and attempt to predict human spatial behaviour in urban environments.

The aforementioned methods were further developed in the urban analysis methodology known as 1st, 2nd 3rd Order or Three Step Analysis [7] created by Peter de Bois which places special emphasis on the pedestrian trajectory to one of its most significant points within an urban fabric. The analysis done in Amsterdam is shown as an example at Figure 1. This method is directly related to the FPC Frame, Pattern and Circuit Method [8]. This is based on the mapping and optimisation of the link between the physical structure of a public space (frame) the dispersion of the programme, and the socioeconomic landmarks (pattern) and the current network of use and circuits implemented in the system by the inhabitants (circuit).

\section{The Strategic RGBG Model}

The RGBG methodology of urban analysis was developed as a teaching tool by TU Delft professors Peter de Bois and Karen Buurmans [9] over the course of several academic periods, and applied as part of the intensive programme, Exploring the Public City [10].

The Strategic RGBG Model is a dynamic urban analysis and design instrument, based on objective and subjective topological knowledge of the urban space. Its work structure is based on a system of overlapping layers (RGBG is an acronym for Red, Green, Blue and Grey) which highlight the pattern of spaces, functions, destinations and urban landmarks, and indicates the existence or absence of circuits which join them in a hierarchical framework. The information collected, physical data on the urban space, is grouped in work areas, each of which is assigned one of the aforementioned colours. By assessing the plans obtained in the fields of work and their overlapping, it is possible to detect urban conflicts and evaluate the reasons why they have arisen.
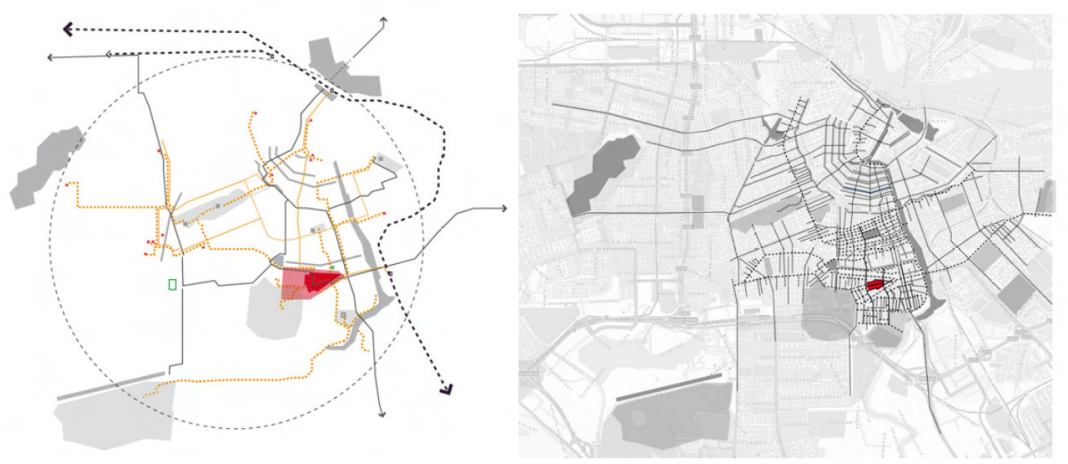

Figure 1: 1, 2, 3 Order Analysis. Cognitive and available frame, Amsterdam [11]. 


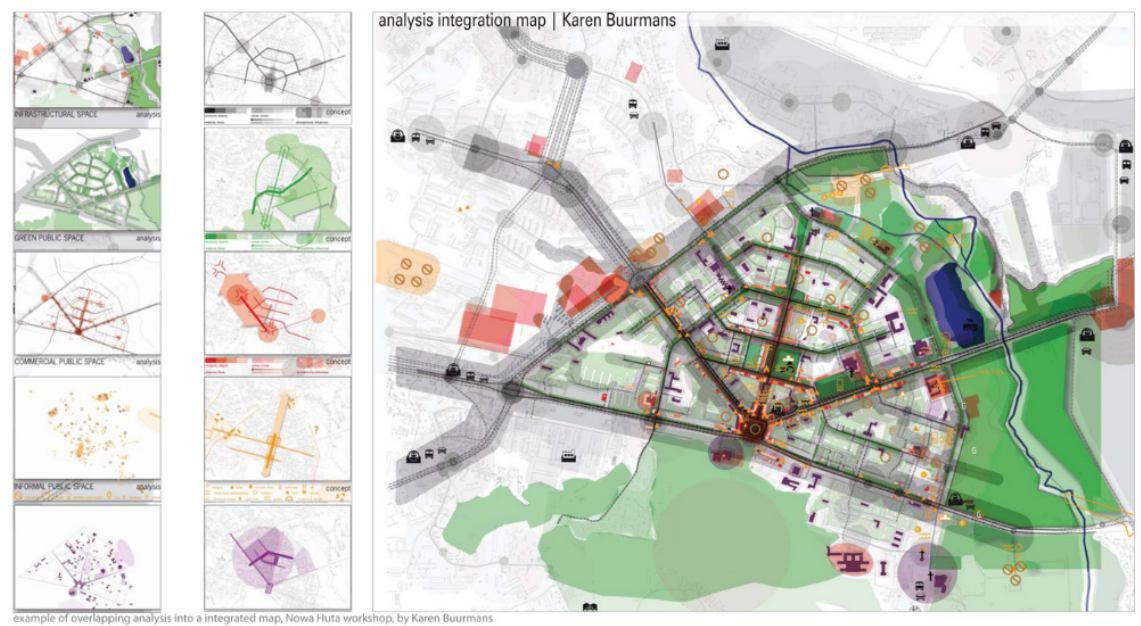

Figure 2: RGBG Analysis. Nowa Huta [12].

Modification of any of the layers, resolving a specific problem of a field of work, makes it possible to assess the impact on the rest of the layers, and therefore future strategies can be defined. The interaction between physical parameters, the structure of the city, permits an assessment of subjective parameters, such as levels of use and how inhabitants perceive their immediate urban surroundings.

As it is stated at Figure 2, analysis of the city of Nowa Huta, the RGBG tool offers the possibility of evaluating the quality of urban public space from different positions:

- The existence and relation between the different activities occurring in the urban public space. Compatibility and incompatibility of activities which permit adequate use of the city space.

- The routes that link the different uses existing in the urban fabric. The facility of moving within the urban fabric in order to reach the landmarks that define the city's structure.

- Through analysis of the city's morphology and the social consequences that this could cause. Existence of informal public spaces or random use, in contrast to formal spaces which are underused.

\section{Municipal district of Orihuela}

Orihuela is one of the most extensive and complex municipal districts on the Spanish Mediterranean coast. The most important urban settlement is the town of Orihuela itself, with 35,000 inhabitants, and located in the interior, between the river Segura and Monte de San Miguel.

As it can be seen at Figure 3, $30 \mathrm{~km}$ from the city of Orihuela lays the urban conglomeration of Orihuela Costa, which has a similar population, and takes up practically the whole coastal fringe in the municipal district of Orihuela $(7 \mathrm{~km})$ getting connected to Torrevieja in the north. 


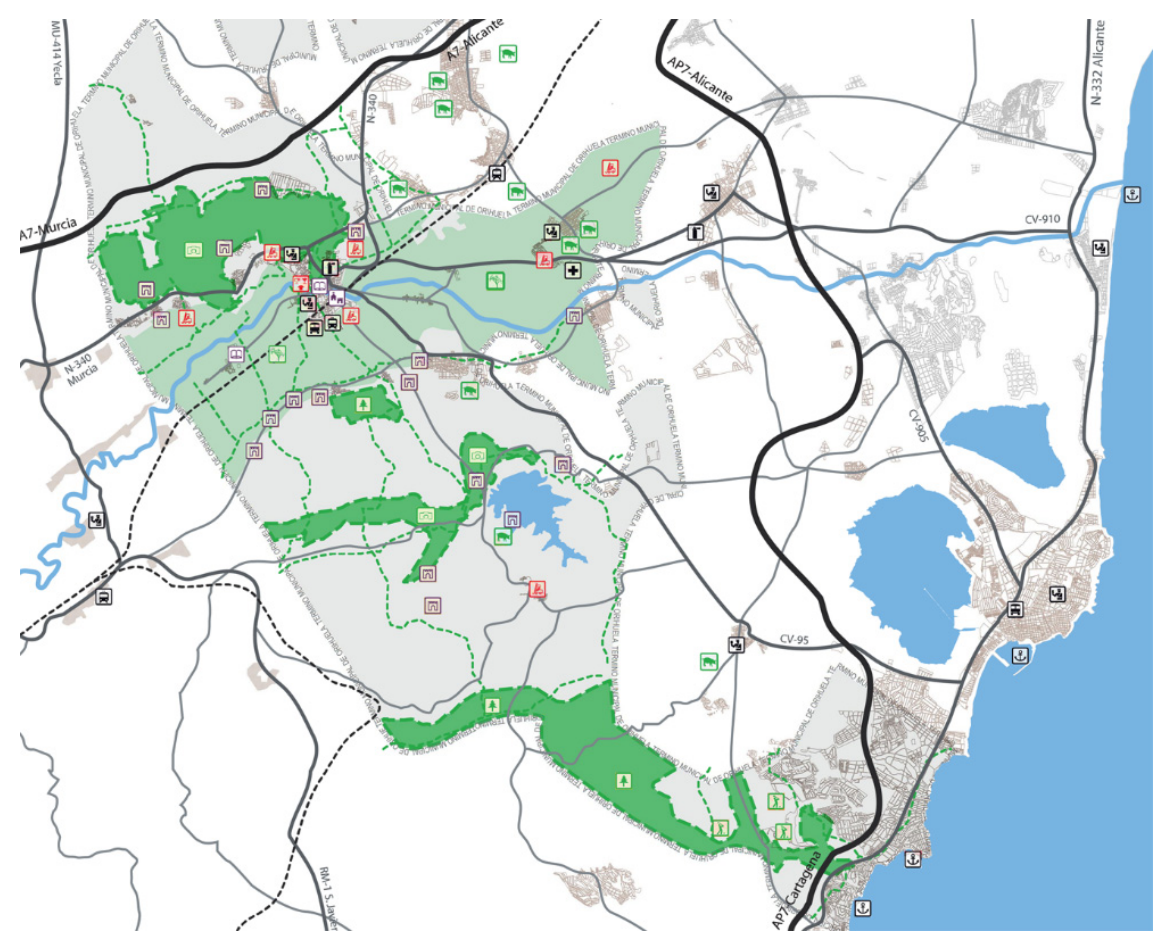

Figure 3: RGBG Analysis. Municipal district of Orihuela (own elaboration).

Distributed over the valley of the Segura River, there are 23 settlements of various sizes and morphologies many of which are linked to water infrastructures.

The town of Orihuela was founded in the Visigoth era. During the Arab period the city expanded around the roads leading to Crevillente, Callosa and Murcia. The rich land of the Rio Segura flood plain made Orihuela the most important city in the Ancient Kingdom of Valencia and as a result it became a bishopric. This fact attracted a number of religious orders who were mainly responsible for constructing the town's significant architectural heritage.

\section{Preliminary analyses carried out by Orihuela Town Council}

In recent years Orihuela Town Council has carried out numerous actions of a sectorial nature with a view to improving the levels of use of the town's urban space. In 2009, in collaboration with the Board of Chambers of Commerce of the Comunidad Valenciana, a Trade Action Plan (PAC) was developed for the town of Orihuela. The subject of the study was the fact that consumers had abandoned the town for other locations, and the failure of small businesses and shopping centres in the immediate vicinity of the town. 
The difficulties of urban mobility, especially in the historic centre, were the subject of a study as part of the Sustainable Urban Mobility Plan drawn up in 2010 between the Town Council and the regional and state authorities.

Initiatives in the historic centre provided incentives to restore its buildings. The Figure 4 shows the protected area within the city centre and remarks the existing monuments. The success of this venture was somewhat patchy given the lack of interest in investing in the area. The Town Council's most recent initiative has been to revise the Special Urban Development and Protection of the Historic Centre Plan in order to update the list of protected buildings.

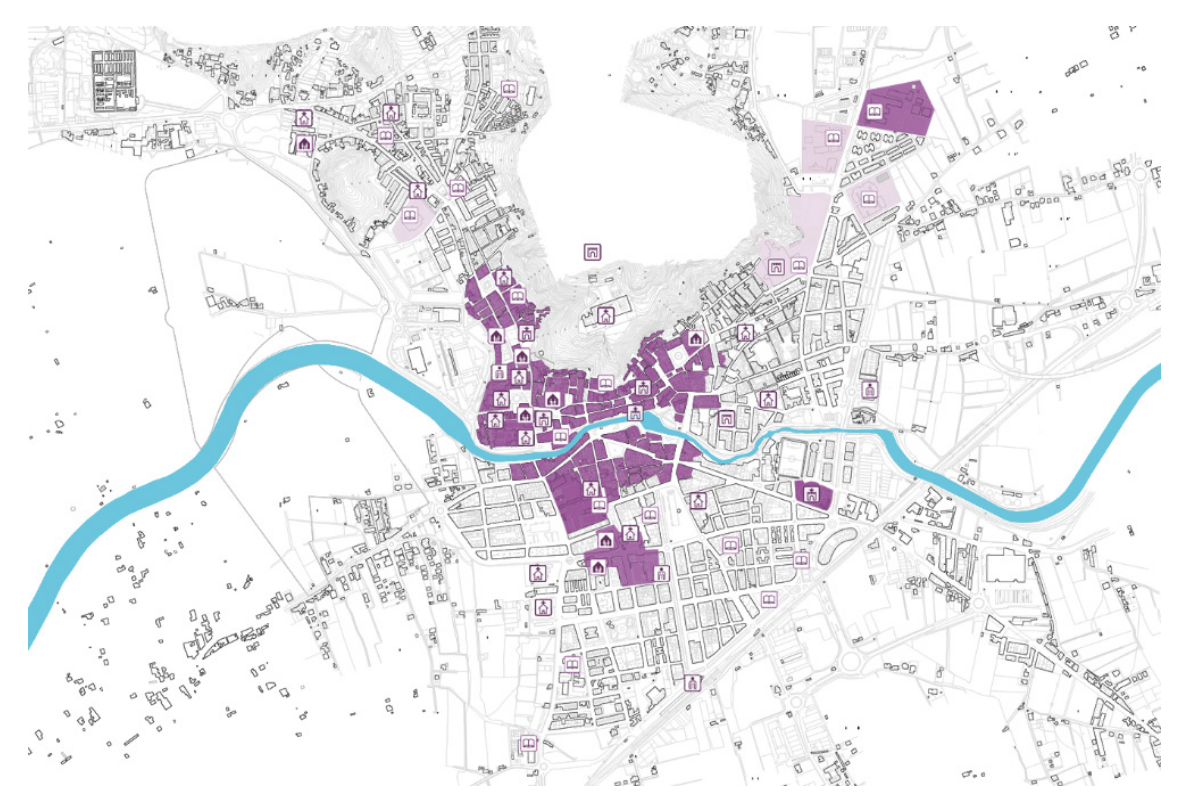

Figure 4: RGBG Analysis. Orihuela's historic centre and monuments.

\section{Revision of the Master Plan for Orihuela and the RGBG Strategic Model tool}

Application of the RGBG Strategic Model was designed to act as a complement to the citizen participation plan described in the revision of the Master Plan for Orihuela. The current master plan which dates from 1990 was obsolete, and the new town planners were required to revise this document. The inordinate levels of development that took place, especially during the 2004-2009 period, has made any proposal for further growth of the town unacceptable with requisite action focusing on the improvement or resolution of the current urban situations that have 
resulted from this unrestrained growth. Orihuela Town Council's willingness to implicate as many social agents as possible in this process led to an agreement with the University of Alicante to carry out an analysis of the municipal district, using the RGBG tool. In this way a research tool, originally applied in an academic context could be used in a real case while at the same time, a public authority was able to benefit from of innovative research techniques.

Application of the RGBG tool in respect of the town was proposed from the perspective of defining four areas of work: infrastructures and mobility (grey), commercial and industrial fabric (red), historic architecture, facilities, leisure and tourism (blue) and territorial green areas, countryside and water infrastructure (green). The information required to make up the interactive layers was facilitated by the various agents taking part and by the research team from the University of Alicante. The information compiled during the process was presented at a series of themed lectures, the Orihuela 2030 Forum, so that in addition to graphic information, the Town Council ceded the chief role of explaining the situation to the agents, institutions and professionals connected with Orihuela, letting them provide their opinions on the town's current status.

\section{Existing urban conflicts and basic premises}

The rapid growth of all the urban settlements in the municipal district of Orihuela has led to a generalised deterioration of the quality of its urban space. The anarchic development of Orihuela Costa and the loss of identity of the surrounding hamlets are the first and most direct conclusions of the urban growth in these areas. The need to find a solution to the territorial mobility and the impact of the infrastructure of the high speed railway line through the area are a priori one of the requirements of Orihuela Town Council. In the urban conglomerate of Orihuela Costa, the initiatives centred on offering solutions to the problems of urban mobility and the cognitive perception that inhabitants have of their urban environment.

Notwithstanding this fact, it is the historic centre of the town of Orihuela where the most important urban conflicts were found, and where most of the research was concentrated.

The oldest parts of the town where most of the monuments are located and which has traditionally been considered the town centre, see Figure 4, is undergoing a process comparable to that which is currently affecting central European towns known as Shrinking Cities [13]. Successive growth of the town has led to city centre developing across the river, gradually distancing it from the historic centre. This process has meant that most of the inhabitants have left the area and most of the businesses have closed. The difficulties of urban mobility and the total lack of connection with Monte San Miguel and the river Segura, traditionally conflictive areas, complete the scenario for application of the RGBG tool. 


\section{Application of the RGBG tool in the urban centre of Orihuela}

\subsection{Commercial and industrial fabric (red)}

As it may be seen in Figure 5, there is no a commercial structure in the city. Shopping areas are disconnected; pedestrians cannot find a continuity that could invite them to cross the city and reach the furthest shopping malls.

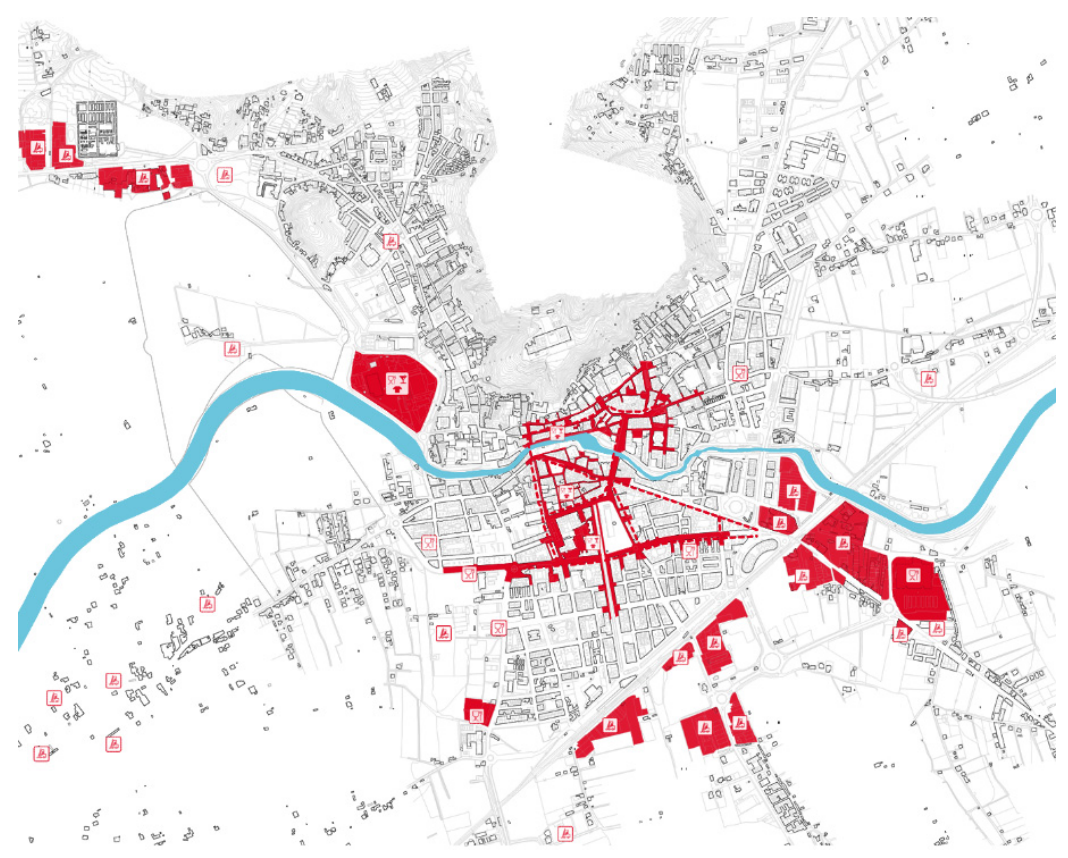

Figure 5: RGBG Strategic Model. Commercial and industrial fabric.

The commercial fabric of Orihuela is concentrated in the main streets of the town centre, mostly on the south bank of the River Segura. Businesses in the historic area have practically disappeared. Outside the urban centre the only other significant shopping areas are two malls, one in the north part of the town close to the Murcia road and the other on the outskirts in the direction of Torrevieja to the south of the town. By the way, the existing rail line is a great barrier that only can be crossed by car making very difficult to reach the south shopping mall.

An analysis of the section of the streets where most of the commercial fabric of the town is located shows that there is no unified urban image and the thoroughfares do not offer an attractive image of the urban space. In the southern part of the river, more importance is given to vehicles than to pedestrians. The sidewalks are narrow and there is little street activity. To the north, within the historic centre, there are pedestrian areas, although the absence of inhabitants means that there is a low intensity of use. 


\subsection{Infrastructures and mobility (grey)}

The main access from the A-7 motorway to the urban centre of Orihuela is from the northeast through the neighbourhood of San Antón and El Palmeral. Entrance to the historic centre, the area north of the river, gives way to a labyrinth of streets with no clear hierarchy and with a one way traffic system. North to the river there are only two streets, one for pedestrians and one for vehicles with very narrow sidewalks. Priority is given to one and others showing in the pedestrian street a high density of people walking during day meanwhile inhabitants disappear from the other street. As may be seen in Figure 6, any change of direction requires crossing the river, leaving the historic centre and then returning to it again.

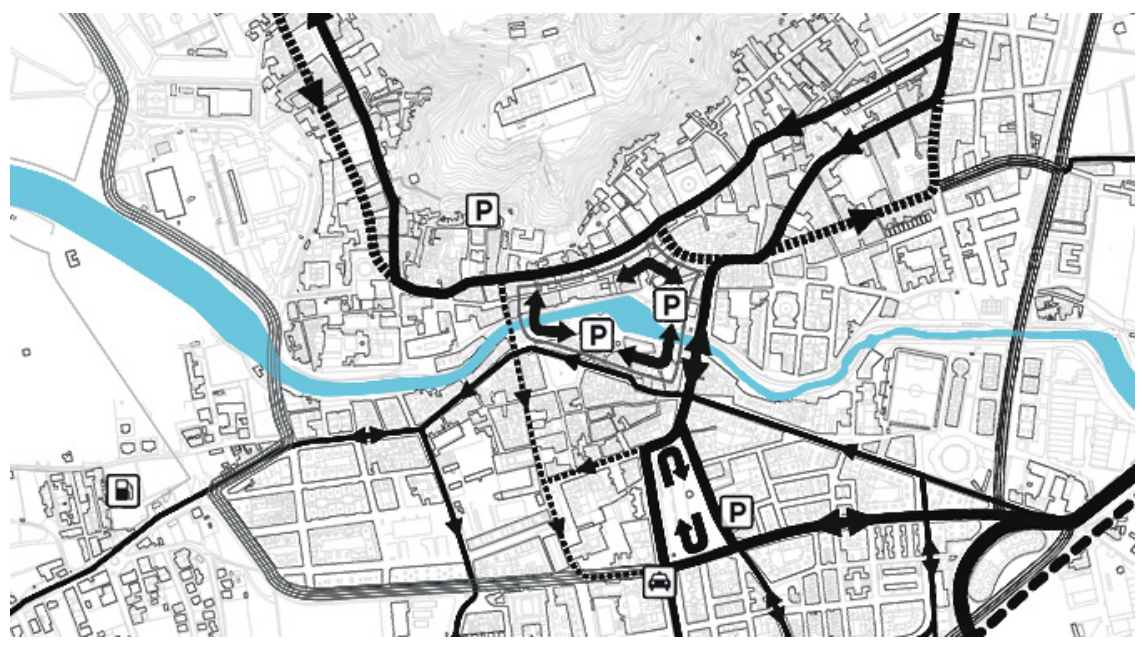

Figure 6: RGBG Strategic Model. Infrastructures and mobility.

There are many streets which end in a cul de sac in part of the historic centre which borders on Monte de San Miguel as there is no transversal connection between them. The urban structure inherited from earlier eras means that any significant point in the urban fabric cannot be reached in a few manoeuvres. In this area is placed the lowest quality housing from the town. In this historic central area there is no parking facility and transit of vehicles is a problem.

\subsection{Territorial green spaces, countryside and water infrastructure (green)}

Orihuela urban centre has inherited the structure of its green spaces from earlier eras. The absence of open spaces is a constant in the medieval towns of south eastern Spain. The presence of squares and gardens is limited, and is always related to monuments or with recent urban refurbishments. However, the town of Orihuela has two matchless landscape elements: the river Segura and El Palmeral. The first is the axis on which the whole town developed and from which all the water courses that irrigate the territory flow, and which led to the numerous urban 
settlements in the countryside area. The second is a forest of palm trees in the northeast of the town which grew as a result of the agricultural developments of the Muslim period. Both elements have scant links with the town. The urban fabric of the town centre has grown up with its back to the river and only in recent times has work been done to make it into a green corridor. As may be seen at the top right part of the Figure 7, El Palmeral is totally cut off from the town centre.

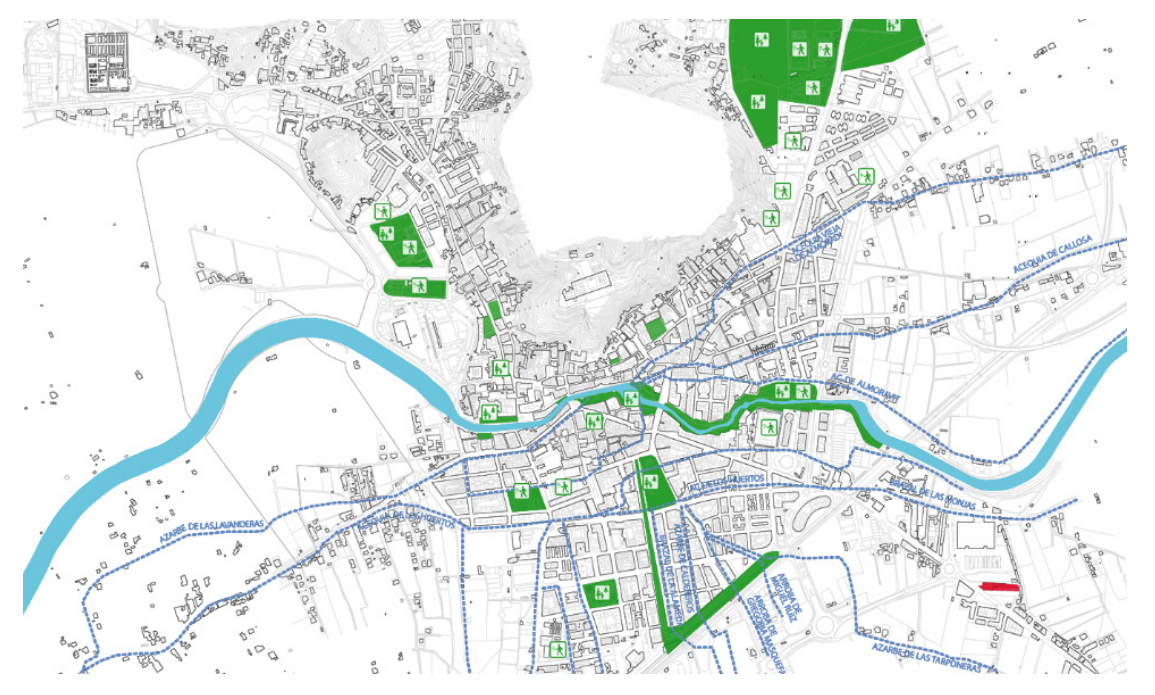

Figure 7: RGBG Strategic Model. Territorial green spaces, countryside and water infrastructure.

\subsection{Historic architecture, facilities, leisure and tourism (blue)}

As shown in Figure 4, the historic centre of Orihuela is rich in cultural and architectural attributes. The excellent state of conservation of many public buildings make the historic centre of Orihuela a place with a potential that few cities or towns could emulate. However, the centre has unevenly exploited, as there are some areas which are extremely run down, with privately owned buildings in ruins and with an extremely high deficit of tertiary uses which hinder optimum levels of urban activity in the zone.

\subsection{Overlapping of layers and conclusions of the analysis}

From overlapping the information of the different areas of work, as it is shown at Figure 8 , it was clear that the difficulties in terms of mobility in the historic centre have conditioned the viability of trade and the existence of substandard housing on the slopes of Monte San Miguel. The section of roads generated one way streets which make it difficult to move about and vehicles take precedence over pedestrians. The lack of parking areas means that visitors with vehicles move to other areas of the town. 


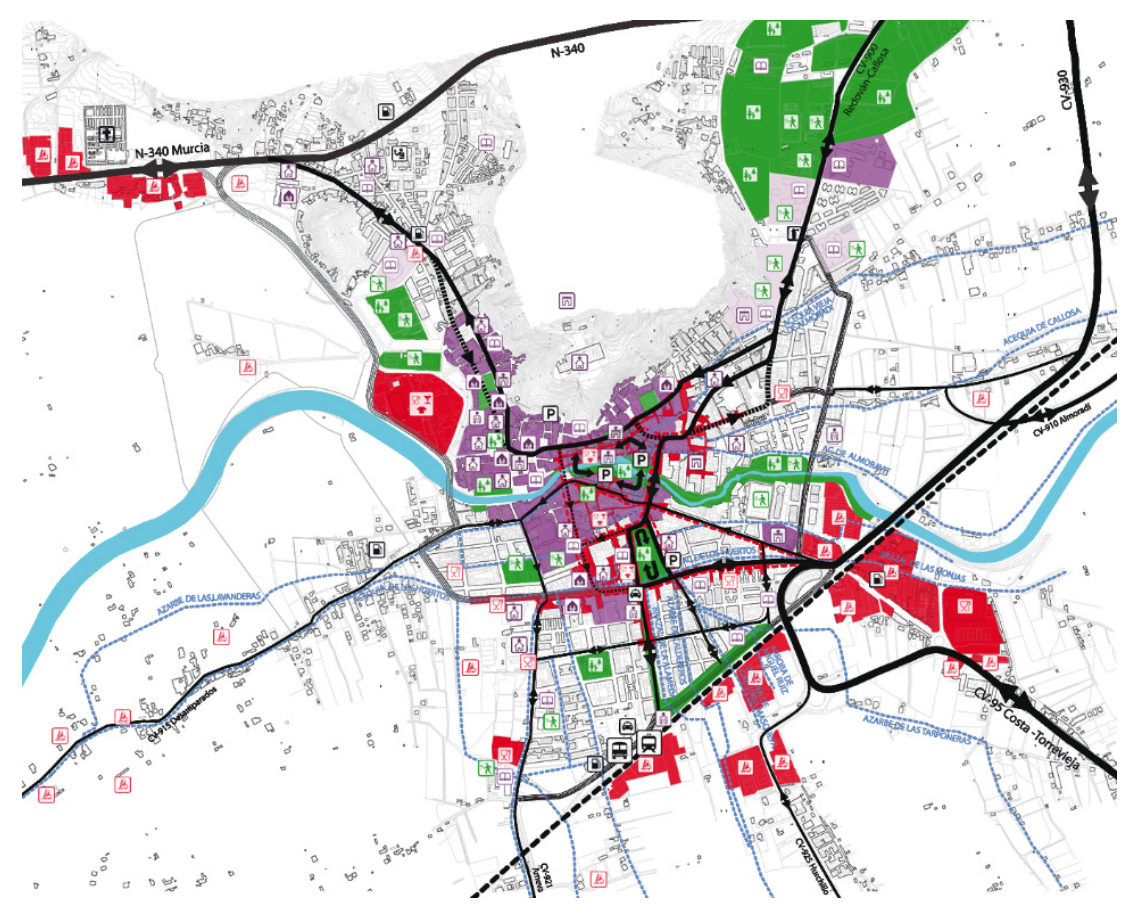

Figure 8: RGBG Strategic Model. Strategic analytical plan.

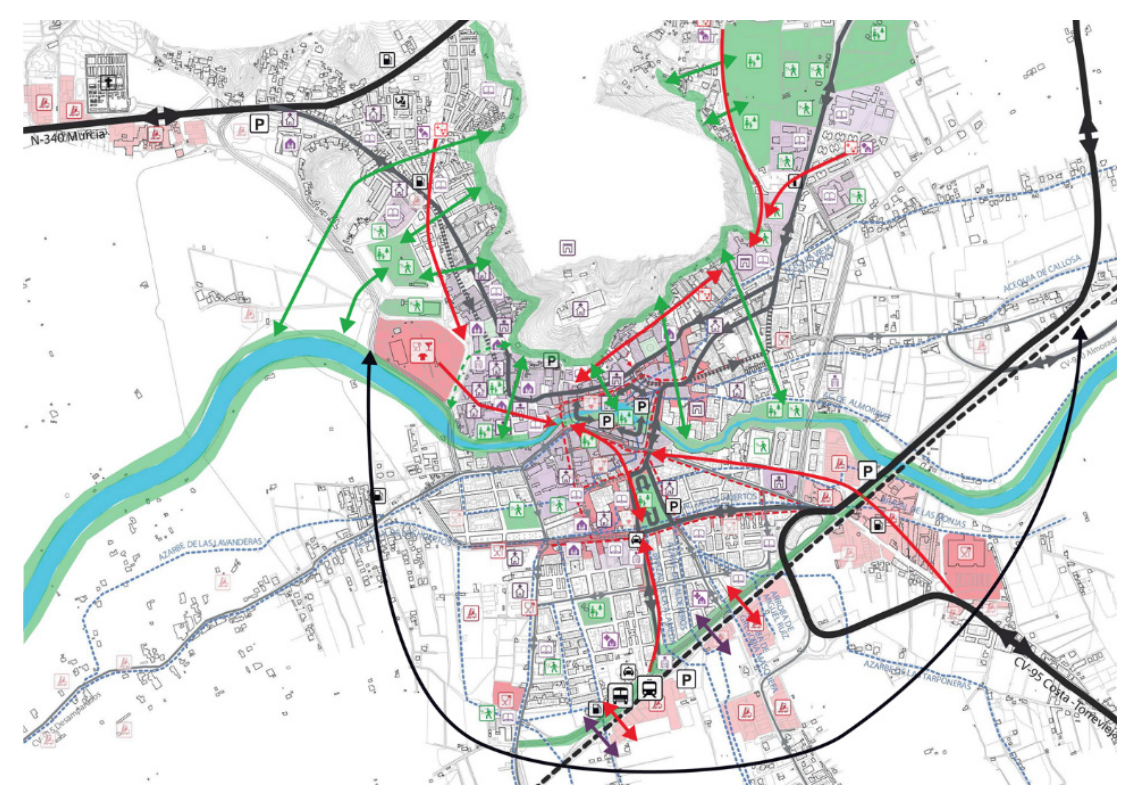

Figure 9: RGBG Strategic Model. Strategic proposal plan. 
The concentration of the commercial and business fabric outside the historic area means that visitors are not attracted to the zone. Despite its extensive architectural heritage, monuments are largely used for religious purposes. Furthermore there is no commercial itinerary, with correct overlapping of uses, which connect the different areas of the town. There is no good structure of green areas in the urban centre of Orihuela. Most public spaces that can be considered green zones are in the historic part of the town and are underused, as they are linked to historic buildings. Larger green areas are linked to subsequent developments of the town and there is no urban green structure which could be extended up to El Palmeral.

\section{Proposals for action}

In order to develop proposals for solving the detected urban conflicts it is used the same strategic plan and by modifying the different RGBG layers, as it can be seen at Figure 9, the results and impact of the actions are analyzed.

\subsection{Commercial and industrial fabric (red)}

In order to improve trade, it is necessary to control the presence of vehicles and modify the street sections, so that the town's image will be improved. The slowing down, or elimination of vehicles, would permit an improved relation between the interior of the buildings and the urban space. A pedestrian itinerary is also required between the commercial areas in order to establish a unified commercial fabric. This itinerary should begin at the railway station and connect both commercial zones, passing through the historic centre where trade would become part of a balanced environment, sharing prominence with existing or future facilities.

\subsection{Infrastructures and mobility (grey)}

Improving accessibility to the historic centre of Orihuela is considered a priority. Therefore it is necessary to prioritise access roads, ensuring greater fluidity and relieving traffic in the town centre. Parking areas are proposed in the intersections of the main access roads to the town in order to reduce the presence of vehicles in the urban centre, thus giving priority to pedestrians. In order to resolve mobility conflicts, closure of the ring road surrounding the town needs to be completed in the south to prevent vehicles accessing the town centre.

\subsection{Territorial green spaces, countryside and water infrastructure (green)}

Creation of a green structure connecting the river, Monte de San Miguel and El Palmeral should be prioritised. This green itinerary would include a route connecting the roads that end in the Monte de San Miguel so that the presence of visitors could increase activity levels in the area and attract improvements to the zone. 


\subsection{Historic architecture, facilities, leisure and tourism (blue)}

Amplification of possible uses of buildings in the historic centre is proposed as essential in order to attract pedestrians, and subsequently trade. In order to attract visitors the area needs better access and an enhanced image of the town. New facilities are needed in connection with the commercial itineraries and a newly created green structure.

\section{Conclusions}

The RGBG Strategic Model is designed to provide a valid alternative as an urban analysis methodology which examines the physical environment with subjective parameters such as levels of activity in the urban public space. The sequential compilation of data, ordered in layers and subsequent overlapping permits an analysis of the situation of the urban space by sector and detection of existing conflicts.

RGBG, through a definition of the areas of work enables social agents and professionals in Orihuela to participate, thus enriching the revision process of an urban planning tool which will govern growth of the town in the coming years. The viability of the conclusions obtained will depend on the development and compliance with the terms of this urban plan.

\section{Acknowledgements}

Development of the intensive programme, Exploring the Public City, was possible thanks to a grant from the Autonomous Organisation of European Educational Programmes (OAPEE) attached to the Ministry of Cultural, Education and Sports of Spain and the support of the six participating universities.

The Orihuela 2030 Forum is an initiative promoted by Orihuela Town Council which commissioned the University of Alicante to apply its RGBG tool to the process of revising the Master Plan. Compilation for the information for each of the fields of work was possible thanks to the endeavours of the institutions, agents and professionals in the town of Orihuela who took part in this activity.

\section{References}

[1] Nolli, Giambattista. "La nuova topografía di Roma Comasco 1748". The Nolli Plan of Rome: Facsimile. Architectura \& Natura Press, Amsterdam, 1991.

[2] Gehl, Jan. "Life between Buildings: using Public Space". Danish Architectural Press, Copenhagen, 1971.

[3] Cerdá, Ildefonso. "Plan de Reforma y Ensanche de la Ciudad de Barcelona". Barcelona, 1860.

[4] Reijndorp, Arnold; Hajer, Maarten. "In search of new public domain. Analysis and strategy". NAI publishers. Rotterdam, 2001. 
[5] Lynch, Kevin. "The image of the city". MIT Press. Cambridge Massachussets, 1960.

[6] Hillier, Bill; Hanson, Julienne. "The social logic of space". Barlett School of Architecture and Planning. Cambridge University Press, Cambridge, 1984.

[7] De Bois, Peter; Buurmans, Karen. "To know the path is to rule the system. Case study New Town Almere (NL)". Delft University of Technology. Deflt, 2007.

[8] Buurmans, Karen. "To know the path is to rule the system. Frame - Âttern - Circuit analysis (FPC)", at Proceedings 10 ${ }^{\text {th }}$ Anniversary Conference European Urban Research Association (EURA), The Vital City. Glasgow, 2007.

[9] De Bois, Peter; Buurmans, Karen. "RGBG Strategic Model, a Scenario analysis \& Design method". Delft University of Technology. Delft, 2006.

[10] Galiano, Antonio; Koehler, Marc; De Bonth, Laura; Ivorra, Gabriel. "Exploring the Public City. Strategic public spaces for sustainable new town development". Publicaciones Universidad de Alicante. Alicante, 2009.

[11] De Bois, Peter; Buurmans, Karen. "To know the path is to rule the system. Case study New Town Almere (NL)". Delft University of Technology. Delft, 2007, pp. 3.

[12] Buurmans, Karen; De Bois, Peter; Wicher, Wojtek. "Exploring the Public City. Transforming the Post-War City, Nowa Huta". Cracow University of Technology, Cracow, 2007.

[13] Oswalt, Phillip (Ed.). "Shrinking cities - Volume 1-2: International Research". Kulturstiftung des Bundes. Berlin, 2005-2006. 